\title{
Synergistic interaction of benign prostatic hyperplasia and prostatitis on prostate cancer risk
}

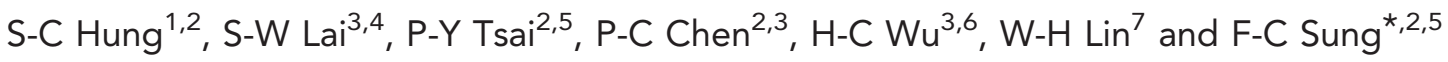

${ }^{1}$ Department of Emergency Medicine, Nantou Hospital, Nantou, Taiwan; ${ }^{2}$ Department of Public Health, China Medical University, Taichung, Taiwan; ${ }^{3}$ School of Medicine, China Medical University, Taichung, Taiwan; ${ }^{4}$ Division of Family Medicine, China Medical University Hospital, Taichung, Taiwan; ${ }^{5}$ Management Office for Health Data, China Medical University Hospital, Taichung, Taiwan; ${ }^{6}$ Division of Urology, China Medical University Hospital, Taichung, Taiwan and ${ }^{7}$ Department of Urology, Nantou Hospital, Nantou, Taiwan

Background: The incidence of prostate cancer is much lower in Asian men than in Western men. This study investigated whether prostate cancer is associated with prostatitis, benign prostatic hyperplasia (BPH), and other medical conditions in the lowincidence population.

Methods: From the claims data obtained from the universal National Health Insurance of Taiwan, we identified 1184 patients with prostate cancer diagnosed from 1997 to 2008. Controls comprised 4736 men randomly selected from a cancer-free population. Both groups were 50 years of age or above. Medical histories between the two groups were compared.

Results: Multivariate logistic regression analysis showed that prostatitis and BPH had stronger association with prostate cancer than the other medical conditions tested. Compared with men without prostatitis and $\mathrm{BPH}$, a higher odds ratio (OR) for prostate cancer was associated with BPH (26.2, 95\% confidence interval (Cl) 20.8-33.0) than with prostatitis $(10.5,95 \% \mathrm{Cl}=3.36-32.7)$. Men with both conditions had an OR of $49.2(95 \% \mathrm{Cl}=34.7-69.9)$.

Conclusion: Men with prostate cancer have strong association with prostatitis and/or BPH. Prostatitis interacts with BPH, resulting in higher estimated relative risk of prostate cancer in men suffering from both conditions.

Prostate cancer is the most common cancer that affects men in Western countries, particularly in the United States (Klein et al, 2007; Jemal et al, 2009, 2010). The incidence and prevalence of prostate cancer in the United States have continuously increased since the introduction of prostate-specific antigen (PSA) screen test in 1992. Among the 217730 new cases estimated in 2010, prostate cancer accounted for $28 \%$ of all cancers in American men. This cancer was also responsible for $22.2 \%(n=382000)$ of cancers that affected men in 40 European countries in 2008 (Ferlay et al, 2010) and $31.2 \%(n=19403)$ of cancers in Australian men in 2007 (Australian Institute of Health and Welfare and; Australasian Association of Cancer Registries (2010)). Although the incidence is much lower in Asian men than in Western men, the incidence rate of prostate cancer has continuously increased in recent decades (Pu et al, 2004). According to the Taiwan Cancer Registry Report, the incidence of prostate cancer increased from 7.5/100 000 in 1992 to $23.5 / 100000$ in 2007 (Taiwan Cancer Registry, 2010). Furthermore, the clinical outcome of localised prostate cancer post-radical prostatectomy has been unsatisfactory, and mortality due to prostate cancer is increasing in Taiwan (Huang et al, 2010; Tseng, 2011).

Relatively little is known about the risk factors associated with the increasing trend of prostate cancer in Asian men, other than the fact that prostate cancer is highly related to aging, ethnicity, 
and family history of prostate cancer (Hsing and Chokkalingam, 2006; Klein et al, 2007). Much attention has recently been given to the roles of chronic inflammation and infection in the pathogenesis and progression of prostate cancer (Kramer et al, 2007; Drake, 2010; De Nunzio et al, 2011). The literature has suggested the association between prostatitis, benign prostatic hyperplasia (BPH), and prostate cancer. van Vuuren et al (2012) considered prostatitis as an early sign of cancer for men with adenocarcinoma of the prostate. Components of metabolic syndromes and $\mathrm{BPH}$ are also strongly related to aging (Klein et al, 2007). These metabolic syndromes may contribute to the development of $\mathrm{BPH}$ and clinical prostate cancer (Hammarsten and Hogstedt, 2002). Prostate cancer screening in symptomatic BPH patients is, therefore, of great concern for men, particularly when the alternative therapies used do not involve tissue pathological analysis (Hall et al, 1996).

The results of studies on the risk of prostate cancer associated with prostatitis and $\mathrm{BPH}$ using population-based data remain inconclusive. In particular, studies on this association are limited for Asian men. We suspect that the mechanism through which prostatitis and $\mathrm{BPH}$ contribute to prostate cancer in Asian men is different from Western men, primarily because the incidence of the said cancer type is much rarer in Asian men ( $\mathrm{Pu}$ et al, 2004; Taiwan Cancer Registry, 2010). Using a population-based data set with information on the medical conditions available for men with low cancer incidence to investigate the said mechanisms can aid in clarifying the association between prostate cancer and prostatitis and $\mathrm{BPH}$. We, therefore, used the data from universal insurance claims to investigate whether prostatitis and $\mathrm{BPH}$ contribute in the risk of prostate cancer in Taiwanese men. In addition to $\mathrm{BPH}$ and prostatitis, this study also explored comorbidities that may be associated with the risk of prostate cancer.

\section{MATERIALS AND METHODS}

Data sources. This study used the 1996-2008 reimbursement claims submitted to the National Health Insurance programme, a universal insurance system established by the Bureau of National Health Insurance of the Department of Health in Taiwan. This insurance programme has covered $>99 \%$ of the population since 1999 (Cheng, 2003). The data set consisted of claims from 1000000 people randomly selected from a total of 23 million insured individuals based on the year 2000 population. In these claims, information on socio-demographic status was available, in addition to health care visits of in-patients and out-patients, from 1996 to 2008. The electronic data files were obtained from the National Health Research Institutes. The identification numbers of all the patients were scrambled to ensure patient confidentiality. This study was, therefore, exempted from full institutional review. We used the International Codes of Diseases 9th Revision, Clinical Modification (ICD-9-CM) to identify diseases.

Study subjects. We identified men aged 50 years and above with primary prostate cancer (ICD-9-CM 185 or A-code A124) diagnosed during the period of 1997-2008 as the sample population. For each prostate cancer patient, four controls comprising cancer-free men at the age of 50 and above were randomly selected from the same data set within the same time period. The age of a study subject was defined according to the date when the patient was diagnosed with prostate cancer or when the control was selected. To explore the potential comorbidities associated with increased risk of prostate cancer, we screened the medical history to search for comorbidities that existed before the identification of the study subjects. Metabolism syndrome and infection have been previously studied as risk factors associated with prostate cancer (Hammarsten and Hogstedt, 2002; Kramer et al, 2007; Drake, 2010; De Nunzio et al, 2011; Taylor et al, 2005). Comorbidities including diabetes mellitus (ICD-9-CM 250 or A-code A181), hypertension (ICD-9-CM 401-405 or A-code A260, A269), hyperlipidemia (ICD-9-CM 272 or A-code A182), prostatitis (ICD-9-CM 601.X), testitis and epididymitis (604.X), gonorrhoea and chlamydia infection (ICD-9-CM 098.X, 099.X), BPH (ICD-9-CM 600 or A-code A360), and obesity (ICD-9-CM 278.00, 278.01 or A-code A183) were included as covariates in this study.

\begin{tabular}{|c|c|c|c|c|c|c|c|}
\hline & & & \multicolumn{4}{|c|}{ Prostate cancer } & \multirow[b]{3}{*}{$P$-value ${ }^{*}$} \\
\hline & \multicolumn{2}{|c|}{ Total, $N=5920$} & \multicolumn{2}{|c|}{ No, $N=4736$} & \multicolumn{2}{|c|}{ Yes, $N=1184$} & \\
\hline & $N$ & $\%$ & $N$ & $\%$ & $N$ & $\%$ & \\
\hline Age group (years) & & & & & & & $<0.0001$ \\
\hline $\begin{array}{l}50-64 \\
65-74 \\
\geqslant 75 \\
\text { Mean (s.d.) }\end{array}$ & $\begin{array}{l}2765 \\
1610 \\
1545 \\
66.9 \\
\end{array}$ & $\begin{array}{c}46.7 \\
27.2 \\
26.1 \\
(11.4) \\
\end{array}$ & $\begin{array}{l}2611 \\
1162 \\
963 \\
65.0 \\
\end{array}$ & $\begin{array}{c}55.1 \\
24.5 \\
20.3 \\
(11.4)\end{array}$ & $\begin{array}{l}154 \\
448 \\
582 \\
74.4 \\
\end{array}$ & $\begin{array}{l}13.0 \\
37.8 \\
49.2 \\
(8.1) \\
\end{array}$ & $<0.0001$ \\
\hline \multicolumn{8}{|l|}{ Comorbidity and medication ${ }^{a}$} \\
\hline $\begin{array}{l}\text { Diabetes mellitus } \\
\text { Hypertension } \\
\text { Hyperlipidemia } \\
\text { Prostatitis } \\
\text { Testitis and epididymitis } \\
\text { Gonorrhoea and chlamydia infection } \\
\text { Benign prostatic hyperplasia } \\
\text { Obesity }\end{array}$ & $\begin{array}{c}704 \\
2739 \\
1217 \\
236 \\
48 \\
16 \\
2155 \\
17\end{array}$ & $\begin{array}{l}11.9 \\
46.3 \\
20.6 \\
3.99 \\
0.81 \\
0.27 \\
36.4 \\
0.29\end{array}$ & $\begin{array}{c}530 \\
1951 \\
869 \\
99 \\
31 \\
11 \\
1071 \\
11\end{array}$ & $\begin{array}{l}11.2 \\
41.2 \\
18.4 \\
2.09 \\
0.65 \\
0.23 \\
22.6 \\
0.23\end{array}$ & $\begin{array}{c}174 \\
788 \\
348 \\
137 \\
17 \\
5 \\
1084 \\
6\end{array}$ & $\begin{array}{l}14.7 \\
66.6 \\
29.4 \\
11.6 \\
1.44 \\
0.42 \\
91.6 \\
0.51\end{array}$ & $\begin{array}{c}0.0009 \\
<0.0001 \\
<0.0001 \\
<0.0001 \\
0.007 \\
0.26 \\
<0.0001 \\
0.11\end{array}$ \\
\hline
\end{tabular}


Table 2. Logistic regression model measured ORs and $95 \% \mathrm{Cls}$ of prostate cancer associated with prostatitis, $\mathrm{BPH}$, and other covariates

\begin{tabular}{|c|c|c|c|c|}
\hline & \multicolumn{2}{|c|}{ Crude } & \multicolumn{2}{|c|}{ Adjusted $^{a}$} \\
\hline Variable & OR & $(95 \% \mathrm{Cl})$ & OR & $(95 \% \mathrm{Cl})$ \\
\hline \multicolumn{5}{|c|}{ Age group (years) } \\
\hline $50-64$ & 1.00 & (reference) & 1.00 & (reference) \\
\hline $65-74$ & 6.54 & $(5.38-7.95)$ & 3.05 & $(2.43-3.83)$ \\
\hline$\geqslant 75$ & 10.2 & $(8.45-12.4)$ & 3.97 & $(3.16-4.98)$ \\
\hline \multicolumn{5}{|c|}{ Diabetes mellitus } \\
\hline Yes & 1.37 & $(1.14-1.64)$ & 0.70 & $(0.56-0.88)$ \\
\hline \multicolumn{5}{|l|}{ Hypertension } \\
\hline Yes & 2.84 & $(2.49-3.25)$ & 1.03 & $(0.97-1.24)$ \\
\hline \multicolumn{5}{|l|}{ Hyperlipidemia } \\
\hline Yes & 1.85 & $(1.60-2.14)$ & 1.24 & $(1.02-1.50)$ \\
\hline \multicolumn{5}{|l|}{ Prostatitis } \\
\hline Yes & 6.13 & $(4.69-8.00)$ & 9.77 & $(3.09-30.9)$ \\
\hline \multicolumn{5}{|c|}{ Testitis and epididymitis } \\
\hline Yes & 2.21 & $(1.22-4.01)$ & 0.66 & $(0.34-1.29)$ \\
\hline \multicolumn{5}{|l|}{ BPH } \\
\hline Yes & 37.1 & $(29.9-46.0)$ & 24.9 & $(19.8-31.4)$ \\
\hline Prostatitis $\times \mathrm{BPH}$ & 7.09 & $(5.35-9.41)$ & 5.17 & $(1.58-17.0)$ \\
\hline \multicolumn{5}{|c|}{$\begin{array}{l}\text { Abbreviations: } \mathrm{BPH}=\text { benign prostatic hyperplasia; } \mathrm{Cl}=\text { confidence interval; } \mathrm{OR}=\text { odds } \\
\text { ratio. } \\
{ }^{\mathrm{a}} \text { Multivariate analysis including age, diabetes mellitus, hypertension, hyperlipidemia, } \\
\text { prostatitis, testits and epididymitis and } \mathrm{BPH} \text {. }\end{array}$} \\
\hline
\end{tabular}

Statistical analysis. In the data analysis, we first compared the distributions of age and comorbidities between cases and controls. $\chi^{2}$-test and $t$-test were used to compare differences between cases and controls for categorical variables and continuous variables, respectively. The significant variables were further included in the multivariate logistic regression analysis to measure the odds ratio (OR) at 95\% confidence interval (CI) for the prostate cancerassociated covariates. Data analysis further verified the role of the interaction between prostatitis and $\mathrm{BPH}$ in the development of prostate cancer. All tests were two-tailed, and a $P$-value $<0.05$ was considered to indicate statistical significance. Statistical analyses were performed using the statistical package SAS for Windows (version 9.1 SAS Institute Inc., Cary, NC, USA).

\section{RESULTS}

This study consisted of 1184 prostate cancer cases and 4736 cancer-free controls. Cases were $\sim 10$ years older than controls, as suggested by the mean age $(P<0.0001)$ (Table 1$)$. Compared with the controls, cases were more prone to diabetes (14.7\% vs $11.2 \%)$, hypertension $(66.6 \%$ vs $41.2 \%)$, hyperlipidemia $(29.4 \%$ vs $18.4 \%)$, prostatitis ( $11.6 \%$ vs $2.09 \%)$, testitis and epididymitis (1.44\% vs $0.65 \%)$, and $\mathrm{BPH}(91.6 \%$ vs $22.6 \%)$.

In the multivariate logistic regression model, compared with the 50- to 64-year-old age group, older patients were at higher odds of prostate cancer, with an OR of $3.05(95 \% \mathrm{CI}=2.43-3.83)$ for the 65- 74-year-old age group, and 3.97 (95\% CI $=3.16-4.98)$
Table 3. Interaction between prostatitis and benign prostatic hyperplasia $(\mathrm{BPH})$ in predicting prostate cancer risk

\begin{tabular}{|c|c|c|c|c|c|}
\hline Prostatitis & $\mathrm{BPH}$ & $\begin{array}{c}\text { Case } \\
(N)\end{array}$ & $\begin{array}{c}\text { Control } \\
(N)\end{array}$ & $\begin{array}{c}\text { Crude } \\
\text { OR }(95 \% \mathrm{Cl})\end{array}$ & $\begin{array}{l}\text { Adjusted OR } \\
(95 \% \mathrm{Cl})\end{array}$ \\
\hline No & No & 96 & 3649 & 1.00 (reference) & 1.00 (reference) \\
\hline No & Yes & 951 & 988 & $36.6(29.3-45.7)$ & $26.2(20.8-33.0)$ \\
\hline Yes & No & 4 & 16 & $9.50(3.12-29.0)$ & $10.5(3.36-32.7)$ \\
\hline Yes & Yes & 133 & 83 & $60.9(43.3-85.7)$ & $49.2(34.7-69.9)$ \\
\hline
\end{tabular}

for the $\geqslant 75$-year-old age group (Table 2). Among comorbidities, a high estimated relative risk for prostate cancer was observed in men with prostatitis $(\mathrm{OR}=9.77,95 \% \mathrm{CI}=3.09-30.9)$ and $\mathrm{BPH}$ $(\mathrm{OR}=24.9,95 \% \mathrm{CI}=19.8-31.4)$. The interaction term of prostatitis $\times \mathrm{BPH}$ was also significant with an OR of $5.17(95 \%$ $\mathrm{CI}=1.58-17.0)$.

Table 3 shows the results of the stratified analysis for the demonstration of the interaction between prostatitis and $\mathrm{BPH}$ in predicting prostate cancer. Compared with patients without both prostatitis and $\mathrm{BPH}$, patients with history of both diseases were at the highest odds for prostate cancer development, with adjusted OR of 49.2 (95\% CI $=34.7-69.9)$. BPH (OR=26.2, 95\% $\mathrm{CI}=20.8-33.0)$ was also found to have a much stronger association with prostate cancer than prostatitis $(\mathrm{OR}=10.5,95 \%$ $\mathrm{CI}=3.36-32.7)$.

\section{DISCUSSION}

Based on the data set in this study, the calculated average incidence of prostate cancer was around 19.7/100 000 for men aged 50 years and above from 1997 to 2008 in Taiwan (data not shown), which was in agreement with the incidence trend officially reported by the Taiwan Cancer Registry, namely, 7.5-23.5/100000 in 1992-2007 (Taiwan Cancer Registry, 2010). A decline of prostate cancer incidence was noted in the United States and in some European countries, but not in Taiwan (Bray et al, 2010). Some studies have suggested that the trend of prostate cancer incidence is mainly affected by the availability of PSA testing and screening programs. No regular extensive PSA screening programme existed in Taiwan before the reformation of the universal health insurance programme. This test has become easily available for men as part of the national health insurance routine checkup since 1996, particularly for men who complain about low urinary track symptoms. The persisting elevated incidence of prostate cancer and the possible risk associated with it should not be ignored.

In this study, age was found to be highly related to the incidence of prostate cancer. The prevalence of metabolic syndromes is also related to age. To determine the relationship between prostate cancer and other comorbidities, we investigated the metabolic syndromes available in the data of the reimbursement claims. The relationships between prostate cancer, obesity, and metabolic syndromes remain inconclusive (Hsing et al, 2007; Gorbachinsky et al, 2010). We failed to identify a significant relationship between prostate cancer and the components of metabolic syndromes, including hypertension, hyperlipidemia, and obesity.

One interesting observation is that diabetes mellitus may have a protective relationship with prostate cancer. The association of diabetes mellitus with cancers has been widely discussed, and most studies found negative relationship or non-specific relationship between diabetes mellitus and prostate cancer. Recent cohort 
studies using the same claim data of the National Health Insurance in Taiwan found weak linkages between diabetes mellitus and prostate cancer (Tseng, 2011), possibly because the follow-up period is not sufficient. The carcinogenesis process is complicated and taking a long latent period. Thus, a short follow-up period may not be sufficient to observe the interaction between diabetes mellitus and various anti-diabetic drugs as oncogenes (Feng et al, 2011; Pettaway et al, 2011).

This study found that prostate cancer is associated with prostatitis and $\mathrm{BPH}$. The human prostate has four zones: peripheral, central, transitional, and fibromuscular stroma. Normally, BPH appears in the central part of the prostate and may induce low urinary tract syndrome earlier than prostate cancer development. However, this incident is unusual because most prostate cancers occur in the peripheral zone (McNeal et al, 1988; Pavelic and Zeljko, 2002). The causal relationship among $\mathrm{BPH}$, prostatitis, and prostate cancer has been a point of controversy because they are strongly associated with similar risk factors, in addition to age (Dennis et al, 2002; Roberts et al, 2004; De Nunzio et al, 2011; Schenk et al, 2011; Chang and Kirby, 2012). Moreover, patients with $\mathrm{BPH}$ symptoms may have a greater urge to visit urologists, and thus, have a higher chance to detect whether they are afflicted with prostate cancer. The relationship appears in this study is much greater than that reported for Western men. An 11-year follow-up study from a single health system has recently reported that the incidences of prostate cancer are $9 \%$ in men with $\mathrm{BPH}$, including $14.3 \%$ in African-American and $7.3 \%$ in Caucasian men (Pettaway et al, 2011). In the present study, BPH was found to be strongly associated with prostate cancer in the logistic regression model after normalising the age and other covariates. However, we were unable to identify the site at which the prostate cancer developed from the claims data. Selection bias might also exist, especially in patients who received transurethral retrograde prostectomy (TURP) for $\mathrm{BPH}$. Prostate cancers can be found in $4-15 \%$ of the surgical histology samples, with or without previous clinical suspicion (Dellavedova et al, 2010). However, the strong association between $\mathrm{BPH}$ and prostate cancer may diminish little even if the cases identified by TURP are excluded.

Inflammation is another important factor contributing to cancer progression. Chronic inflammatory conditions are associated with cancer development, such as reflux esophagitis with oesophageal cancer and virus hepatitis with hepatocellular carcinoma. The hypothesis about chronic inflammation inducing carcinogenesis is based on the local irritation associated with the regulation of the inflammatory cells and cytokine (Coussens and Werb, 2002). Both bacteria- and non-bacteria-related prostatitis are, but not sexually transmitted diseases (STDs), significant factors associated with prostate cancer. However, the causality remains unclear (Dennis et al, 2002; Roberts et al, 2004).

Based on six population-based case-control studies and five hospital-based case-control studies, an earlier meta-analysis found a 1.6-fold increased risk of prostate cancer for men with a prostatitis history (Dennis et al, 2002). Studies also found that STDs are potentially associated with increased risk of prostate cancer (Dennis et al, 2002; Taylor et al, 2005). However, the selecting bias and recall bias about the history of prostatitis are concerned in epidemiological studies. Prostatitis could be categorised into four groups: category I comprising acute bacteria prostatitis, category II comprising chronic bacterial prostatitis, category III comprising chronic prostatitis/chronic pelvic pain syndrome, and category IV comprising asymptomatic inflammation prostatitis (Krieger et al, 1999). Category III prostatitis may account for $90 \%$ of diagnosed cases (Krieger et al, 1999), and patients with category IV prostatitis are usually cases that are accidently diagnosed (Habermacher et al, 2006). Delongchamps et al (2008) evaluated 167 autopsied prostates and found that chronic inflammation is commonly associated with $\mathrm{BPH}$, but not the cancer. However, the sample size was probably too small to identify a significant relationship. They found that chronic inflammatory infiltrations are mostly located in the transitional zones instead of the peripheral zone where prostate cancer is usually diagnosed (McNeal et al, 1988; Pavelic and Zeljko, 2002). These pathological findings are valuable for further studies. However, the autopsied findings may not truly reflect the entire past exposure history of prostatitis.

In the present study, patients with prostatitis history may have increased risk of prostate cancer, but not patients with testitis and epididymitis, as well as those with gonorrhoea and chlamydia infection. This result suggests that the localised inflammation effect may have a more important role in carcinogenesis. Compared with previous self-report case-control studies, the high-coverage claims data set may be more reliable in exploring the history of prostatitis and STDs.

Studies have focused on the contribution of inflammation to both BPH and prostate cancer (Alcaraz et al, 2009; De Nunzio et al, 2011). Case-control studies have linked BPH to the risk of prostate cancer for Saudi Arabian men who also have low incidence of the disease (Mosli, 2003; Abdel-Meguid et al, 2009; Alcaraz et al, 2009). Chronic inflammation is associated with BPH and prostate cancer based on medical records and needle biopsy findings (Mosli, 2003; Abdel-Meguid et al, 2009). However, the magnitude of the relationship among these three disorders was not well clarified (Abdel-Meguid et al, 2009).

Our population-based study proved that prostate cancer is associated with prostatitis and BPH. Benign prostatic hyperplasia is a much stronger risk factor than prostatitis in terms of cancer association. Overlap in BPH and prostatitis exists in our study. Patients with prostatitis are more likely to overlap with $\mathrm{BPH}$ in cancer cases than in controls $(97.1 \%$ vs $16.2 \%)$, indicating high linearity between prostatitis and $\mathrm{BPH}$. A strong interaction between prostatitis and $\mathrm{BPH}$ for predicting prostate cancer thus appeared in this study, which culminated with an adjusted OR of 49.2 for men with the history of both prostatitis and $\mathrm{BPH}$. To the best of our knowledge, no previous study has reported such a strong synergistic interaction. The causal association of prostate cancer involving prostatitis and $\mathrm{BPH}$ is inconclusive in studies done on Western men. This association in Asian men is rather different from that in Western men. With a relatively low incidence of prostate cancer, the pattern observed in this research is worthy of further study. In this study, cases are 6.2-fold more likely to have a history of both $\mathrm{BPH}$ and prostatitis than controls (11.9\% vs $1.92 \%)$. The irritation and stimulation from $\mathrm{BPH}$ and prostatitis combined may increase the risk of prostate cancer.

Some medications have been discussed as risk factors for prostate cancer. We also analysed the association with medications that were mostly studied in relation with prostate cancer (Jacobs et al, 2005). Our results showed that only aspirin exhibited a protective association in reducing the risk of prostate cancer (data not shown). This result is consistent with a large cohort study done on the use of aspirin and other non-steroidal anti-inflammatory drugs (NSAIDs) conducted in the United States. Jacobs et al (2005) found that men with long-term regular use of aspirin have reduced risk of prostate cancer ( $\mathrm{RR}=0.85,95 \% \mathrm{CI}=0.73$ to 0.99 ). Their recent study showed long-term regular acetaminophen use may also reduce the overall prostate cancer risk to a relative risk of 0.62 (Jacobs et al, 2011). Although acetaminophen shares the same pathway as NSAID, the anti-inflammation effect is weak. This result may provide information for further explorations on prostate carcinogenesis.

Limitations. This study was limited by the use of data from insurance claims because some information on lifestyle and physical examination status are not available. Thus, we were 
unable to ascertain whether prostate cancer is associated with smoking, drinking, waist measurement, and so on. Data on family history, molecular factors, and pathophysiology examinations were not available as well. However, we found that obesity is not a significant factor associated with the cancer. Patients with prostatitis and/or BPH may have higher odds to be diagnosed with prostate cancer than the controls, primarily because the former group may visit physicians more frequently. Therefore, the risk estimation for prostate cancer might be overestimated. However, the high accessibility and inexpensive national health system make our analysis more reliable. Some concerns may exist regarding the miscoding and over diagnosis of $\mathrm{BPH}$ and prostatitis using the claims data set. The causality of prostate cancer was not established in this study, although $\mathrm{BPH}$ and prostatitis were diagnosed before the diagnosis of prostate cancer. Therefore, the mechanism remains unclear.

\section{CONCLUSIONS}

Although the incidence of prostate cancer is much lower in Taiwanese men than in men from Western countries, the incidence in Taiwan is steadily increasing. Diabetes and taking aspirin may have a protective effect against prostate cancer, but their beneficial effect may be compromised by overall impairment, leading to the development of BPH and/or prostatitis. Patients with the history of $\mathrm{BPH}$ and/or prostatitis could have significantly increased risk of prostate cancer, which is stronger for those with $\mathrm{BPH}$ than those with prostatitis. The odds is much higher for patients with both $\mathrm{BPH}$ and prostatitis.

\section{ACKNOWLEDGEMENTS}

We would like to thank the Taiwan National Health Research Institute for providing the NHI database. This study was partly supported by the National Sciences Council (Grant no. NSC 100-2621-M-039-001), the China Medical University Hospital (Grant no. 1MS1), the Taiwan Department of Health Clinical Trial and Research Centre for Excellence (Grant no. DOH100-TDB-111-004), and the Cancer Research Centre of Excellence (DOH100-TD-C-111-005).

\section{CONFLICT OF INTEREST}

The authors declare no conflict of interest.

\section{REFERENCES}

Abdel-Meguid TA, Mosli HA, Al-Maghrabi JA (2009) Prostate inflammation. Association with benign prostatic hyperplasia and prostate cancer. Saudi Med J 30: 1563-1567.

Alcaraz A, Hammerer P, Tubaro A, Schroder FH, Castro R (2009) Is there evidence of a relationship between benign prostatic hyperplasia and prostate cancer? Findings of a literature review. Eur Urol 55: 864-873.

Australian Institute of Health and Welfare \& Australasian Association of Cancer Registries (2010) Cancer in Australia: an overview. 2010. Cancer series no. 60. Cat. no. CAN 56. Canberra: AIHW. 2010.

Bray F, Lortet-Tieulent J, Ferlay J, Forman D, Auvinen A (2010) Prostate cancer incidence and mortality trends in 37 European countries: an overview. Eur J Cancer 46: 3040-3052.

Chang RT, Kirby R, Challacombe BJ (2012) Is there a link between BPH and prostate cancer? Practitioner 256: 13-16.

Cheng TM (2003) Taiwan's new national health insurance program: genesis and experience so far. Health Aff (Millwood) 22: 61-76.

Coussens LM, Werb Z (2002) Inflammation and cancer. Nature 420: 860-867.
De Nunzio C, Kramer G, Marberger M, Montironi R, Nelson W, Schröder F, Sciarra A, Tubaro A (2011) The controversial relationship between benign prostatic hyperplasia and prostate cancer: the role of inflammation. Eur Urol 60: 106-117.

Dellavedova T, Ponzano R, Racca L, Minuzzi F, Dominguez M (2010) Prostate cancer as incidental finding in transurethral resection. Arch Esp Urol 63: $855-861$.

Delongchamps NB, de la Roza G, Chandan V, Jones R, Sunheimer R, Threatte G, Jumbelic M, Haas GP (2008) Evaluation of prostatitis in autopsied prostates-is chronic inflammation more associated with benign prostatic hyperplasia or cancer? J Urol 179: 1736-1740.

Dennis LK, Lynch CF, Torner JC (2002) Epidemiologic association between prostatitis and prostate cancer. Urology 60: 78-83.

Drake CG (2010) Prostate cancer as a model for tumour immunotherapy. Nat Rev Immunol 10: 580-593.

Feng YH, Velazquez-Torres G, Gully C, Chen J, Lee MH, Yeung SC (2011) The impact of type 2 diabetes and antidiabetic drugs on cancer cell growth. J Cell Mol Med 15: 825-836.

Ferlay J, Parkin DM, Steliarova-Foucher E (2010) Estimates of cancer incidence and mortality in Europe in 2008. Eur J Cancer 46: 765-781.

Gorbachinsky I, Akpinar H, Assimos DG (2010) Metabolic syndrome and urologic diseases. Rev Urol 12: e157-e180.

Habermacher GM, Chason JT, Schaeffer AJ (2006) Prostatitis/chronic pelvic pain syndrome. Annu Rev Med 57: 195-206.

Hall MC, Roehrborn CG, McConnell JD (1996) Is screening for prostate cancer necessary in men with symptoms of benign prostatic hyperplasia? Semin Urol Oncol 14: 122-133.

Hammarsten J, Hogstedt B (2002) Calculated fast-growing benign prostatic hyperplasia-a risk factor for developing clinical prostate cancer. Scand $J$ Urol Nephrol 36: 330-338.

Hsing AW, Chokkalingam AP (2006) Prostate cancer epidemiology. Front Biosci 11: 1388-1413.

Hsing AW, Sakoda LC, Chua Jr S (2007) Obesity, metabolic syndrome, and prostate cancer. Am J Clin Nutr 86: s843-s857.

Huang SP, Huang CY, Liu CC, Yu CC, Pu YS, Chueh SC, Yu HJ, Wu TT, Li CC, Huang CH, Wu WJ (2010) Clinical outcome of Taiwanese men with clinically localized prostate cancer post-radical prostatectomy: a comparison with other ethnic groups. Aging Male 13: 10-17.

Jacobs EJ, Newton CC, Stevens VL, Gapstur SM (2011) A large cohort study of long-term acetaminophen use and prostate cancer incidence. Cancer Epidemiol Biomarkers Prev 20: 1322-1328.

Jacobs EJ, Rodriguez C, Mondul AM, Connell CJ, Henley SJ, Calle EE, Thun MJ (2005) A large cohort study of aspirin and other nonsteroidal anti-inflammatory drugs and prostate cancer incidence. J Natl Cancer Inst 97: 975-980.

Jemal A, Siegel R, Ward E, Hao Y, Xu J, Thun MJ (2009) Cancer statistics. CA Cancer J Clin 59: 225-249.

Jemal A, Siegel R, Xu J, Ward E (2010) Cancer statistics. CA Cancer J Clin 60: 277-300.

Klein EA, Platz EA, Thompson IM (2007) Etiology, and prevention of prostate cancer. In Campbell-Walsh Urology, Wein AJ, Kavoussi LR, Novick AC, Partin AW, Peters CA (eds), 9 edn. pp 2854-2873. Saunders Elsevier: Philadelphia, PA, USA.

Kramer G, Mitteregger D, Marberger M (2007) Is benign prostatic hyperplasia $(\mathrm{BPH})$ an immune inflammatory disease? European urology 51: 1202-1216.

Krieger JN, Nyberg Jr L, Nickel JC (1999) NIH consensus definition and classification of prostatitis. JAMA 282: 236-237.

McNeal JE, Redwine EA, Freiha FS, Stamey TA (1988) Zonal distribution of prostatic adenocarcinoma. Correlation with histologic pattern and direction of spread. Am J Surg Pathol 12: 897-906.

Mosli HA (2003) Prostate cancer in Saudi Arabia in 2002. Saudi Med J 24: $573-581$.

Pavelic J, Zeljko Z (2002) [Prostate gland-transition zone lesions. Etiology, growth regulation, growth factors, genetic changes]. Lijec Vjesn 124: 211-219.

Pettaway CA, Lamerato LE, Eaddy MT, Edwards JK, Hogue SL, Crane MM (2011) Benign prostatic hyperplasia: racial differences in treatment patterns and prostate cancer prevalence. BJU Int 108: 1302-1308.

$\mathrm{Pu}$ YS, Chiang HS, Lin CC, Huang CY, Huang KH, Chen J (2004) Changing trends of prostate cancer in Asia. Aging Male 7: 120-132.

Roberts RO, Bergstralh EJ, Bass SE, Lieber MM, Jacobsen SJ (2004) Prostatitis as a risk factor for prostate cancer. Epidemiology 15: 93-99. 
Schenk JM, Kristal AR, Arnold KB, Tangen CM, Neuhouser ML, Lin DW, White E, Thompson IM (2011) Association of symptomatic benign prostatic hyperplasia and prostate cancer: results from the prostate cancer prevention trial. Am J Epidemiol 173: 1419-1428.

Taiwan Cancer Registry (2010) Cancer Incidence in Taiwan (accessed 29 March 2010). Available at http://tcr.cph.ntu.edu.tw/main.php? Page A5).

Taylor ML, Mainous AG III, Wells BJ (2005) Prostate cancer and sexually transmitted diseases: a meta-analysis. Fam Med 37: 506-512.

Tseng CH (2011) Diabetes and risk of prostate cancer: a study using the National Health Insurance. Diabetes Care 34: 616-621. van Vuuren SP, Heyns CF, Zarrabi AD (2012) Significance of histological prostatitis in patients with urinary retention and underlying benign prostatic hyperplasia or adenocarcinoma of the prostate. BJU Int 109: 1194-1197.

This work is published under the standard license to publish agreement. After 12 months the work will become freely available and the license terms will switch to a Creative Commons AttributionNonCommercial-Share Alike 3.0 Unported License. 